\title{
Don Segundo Sombra y la Desanalfabetización del Héroe
}

En los numerosos estudios sobre la gran novela de Güiraldes se han aclarado dos aspectos suyos que son fundamentales. El primero es una notable peculiaridad lingüística: en una prosa de narrador culto están sabiamente engastados unos diálogos de lenguaje gauchesco. ${ }^{1} \mathrm{Y}$ el segundo es un aspecto del argumento: se trata del rito de pasaje de un niño o muchacho que, bajo la tutela de un maestro, se va convirtiendo en hombre. ${ }^{2}$ Después de repasar brevemente estos dos aspectos, yo quisiera señalar una relación entre ellos.

Es notable en Don Segundo Sombra el acierto estilístico que resulta de la combinación de dos lenguajes claramente diferenciados: utilizando los términos de un Sarmiento, podrỉamos decir que el lenguaje de la civilización, centrada en Buenos Aires y París, abarca aquí al de la barbarie gauchesca. Traslucen dos mundos: el cosmopolita de los libros, y el provinciano de la pampa. No es que se nos presente este último mundo en su propio lenguaje, como parece afirmar Amado Alonso (nota 1): para eso Gûiraldes sí hubiera tenido que "agauchar la lengua literaria general," y no elaborar "literariamente la lengua viva de los provincianos cultos" (Alonso, p. 425). En Huckleberry Finn Mark Twain había procedido de aquella primera manera; pero en Don Segundo Sombra Güiraldes, en las palabras acertadas de Alonso (pp. 423-424), "mantiene una cuidadosa separación entre las formas y locuciones paisanas del diálogo -de legítima asistencia, puesto que supone son consignaciones memoristas de diálogos asî sucedidos- y la prosa literaria de que es directamente responsable el narrados- literato." Hay una misteriosa distancia temporal y cultural entre el joven protagonista y el narrador maduro, distancia claramente señalada por la diglosia ${ }^{3}$ del texto. Es verdad 
que lo narrado es esencialmente la vivencia inmediata del protagonista, que no se refiere nunca el narrador al proceso "posterior" de su propio escribir narrativo; pero nos damos cuenta de que el modo de hablar del protagonista no pertenece a la lengua literaria del narrador, personaje ausente de la acción pero presente por su diferencia como escritor.

Consideremos ahora el aspecto argumental. Según A. Chapman (nota 2, p. 62), Don Segundo Sombra es un Bildungsroman muy especial: "The educational process is conceived as an initiation rite in which a substitute father guides the novice." Los lectores de la novela vislumbramos el mundo crepuscular del mito primitivo: un huérfano sin nombre, ahijado temporalmente a un mestizo centáurico, aprende las duras disciplinas físicas de éste, evitando los engaños mujeriles y pasando por la tierra infernal o laberíntica de los cangrejales, donde mata un gran toro, pierde el conocimiento, y luego se resuscita para escaparse de una Circe y convertirse finalmente en héroe domador de caballos. El ensayo de Chapman, después de iluminar claramente esta dimensión mitológica y ritual de la novela, nos lleva a una conclusión trágica: que al final la madre tierra se convierte en posesión económica, y que los ricos abusan de los pobres en una corrompida cultura moderna. (Pero quizá esta tragedia pertenece más bien al mundo de Faulkner, citado a menudo por Chapman, que no al de Güiraldes.)

En este Bildungsroman, la diglosia del texto, o sea la curiosa distancia lingüistica que existe entre protagonista y narrador, tiene que relacionarse con la educación del protagonista. Su educación en efecto tiene varias etapas. Las preliminares se recapitulan en el capitulo I. Cuando tenía unos siete años de edad, el protagonista fue separado de su "mama" y, bajo la tutela de dos tỉas regañadoras, fue mandado al colegio durante tres años y llevado a misa los domingos. Luego, después de este breve y desagradable contacto con dos instituciones elementales del pueblo, se trasladó a la calle, otra institución mucho más agradable, en la cual aprendió el arte del la agudeza oral. En la casa pública del pueblo sufrió otra iniciación, antes de encontrar en Don Segundo su padrino gauchesco, cuya influencia educacional forma la parte central de la novela, tal como la ha explicado Chapman.

Este mundo del gaucho representa una etapa cultural más antigua que la del pueblo, con sus instituciones más o menos letradas. El gaucho no sólo es funcionalmente analfabeto sino que cultiva el silencio oral. En la estancia de Galván ya empieza Don Segundo a 
suprimir la locuacidad del muchacho: "La lengua parece que la tenés pelada" (cap. IV). Sólo en raras ocasiones festivales (el baile, la riña de gallos, los cuentos) se elaboran unas tradicionales fórmulas orales. Hay por supuesto todo un vocabulario técnico gauchesco; pero este vocabulario sirve sólo transitoriamente para el aprendizaje de actividades físicas que son más bien solitarias o silenciosas. La dureza física, con pocas palabras, lleva implícita una lección de estoica insensibilidad voluntariosa, por lo menos en el caso de Don Segundo (cap. XXIV):

Cuando todos estaban de ida hacia la muerte el venía de vuelta... Pero todos esos pensamientos mios no pasaban de ser más que conjeturas. Verdad era su absoluta indiferencia ante los hechos, a quienes oponía comentarios irónicos. ¿Quién fuera como él! Yo sufrǐa por todo...

Vemos aquí, al mismo final de su educación gauchesca, que el protagonista todavía se diferencia, por su sensibilidad, del admirado padrino y modelo. Y con el capítulo siguiente empieza la conclusión de la novela, es decir, el breve desenlace de tres capittulos, cuya comprensión es esencial para nuestra interpretación.

En el capítulo XXV se cierra un cǐrculo geográfico, lo cual trae al joven recuerdos nostálgicos de felicidades perdidas. Pero uno de estos recuerdos se convierte en un amigo que lo trata de usted, y no ya de vos, y que le entrega un papel. Y esta escritura, con sobre que reza "Señor Fabio Cáceres," le da por fin un nombre, con una herencia y un tutor que ya no es su padrino gauchesco. "El campo, todo me parecia distinto. Miraba desde adentro de otro individuo." Sufre un acceso de sentimientos violentos, queriendo creer "que ese papelito miente." Pero Don Segundo le dice tranquilamente: “... Tu padre era un homre rico como todos los ricos y no había más mal en él. Y no tento otra cosa que decirte, sino que te queda mucho por aprender ..." Continuará su educación. Fabio llama a Don Seguno, por primera vez, "Tata," y empieza a despedirse de sus compañeros: "En los sucesivos apretones de mano, era como si me dijera adiós a mí mismo." Ante esta penosa crisis de identidad social, con simbólico cambio de ropa, Don Segundo afirma una posible continuidad interior: "Si sos gaucho en de versa, no has de mudar, porque andequiera que vayas, irás con tu alma por delante como madrina'e tropilla."

En el capítulo XXVI se realiza lo que habỉa soñado el joven al principio del capitulo XVIII, después de matar el toro y perder el 
conocimiento: ocurre ahora otro rito de pasaje o de muerte simbólica. Se repiten las mismas palabras: “... sentía como si fuera otro ... , otro que había ganado algo grande e indefinido, pero que tenía asimismo una sensación de muerte." Pero esta vez: "Me sentía bien a pesar de mi crisis moral. Tenía una extraña sensación de existencia nueva." $\mathrm{Y}$ es precisamente ahora cuando Fabio conoce al coetáneo que será el padrino de su nueva educación literaria, a Raucho, quien le indica su futura transformación con estas palabras: "Yo soy un cajetilla agauchao y vos, dentro'e poco, vah'a ser un gaucho acajetillado." En esta última etapa educacional el joven empieza a verbalizar sus experiencias, contemplándolas como acciones ya no inmediatas sino mentalmente rememoriadas. "No recordaba haber hablado nunca tanto y hasta me perecia que, por primera vez, pensaba con detenimiento en los episodios de mi existencia. Hasta entonces no tuve tiempo... Me dejaba ir hacia adentro de mí mismo, serenándome en la revisión de lo que fue."

Este proceso de revisión dura tres años, el tiempo que transcurre entre el capítulo penúltimo y el último, el XXVII. Los cuentos y relatos orales de Don Segundo se enlazan en este capittulo con la biblioteca políglota y la fantasia aventurera de Raucho. "A todo esto, poco a poco, me iba formando un nuevo carácter y nuevas aficiones. A mi andar cotidiano sumaba mis primeras inquietudes literarias. Buscaba instruirme con tesón. Pero no quiero hablar de todo eso en estas líneas de alma sencilla ..." Así es como el narrador señala de paso la distancia espiritual entre su prosa culta y lo que quiere narrar por medio de ella. Sólo una cultura literaria podía captar en palabras una experiencia esencialmente analfabeta e incluso poco verbalizada. Cuando Fabio se despide silenciosamente de Don Segundo, se separan los dos mundos diferentes, transformándose el gaucho en idéas y palabras: "Aquello que se alejaba era más una idea que un hombre. Y bruscamente desapareció, quedando mi medicación separada de su motivo." Esta es una separación o interiorización religiosa, recordada en las últimas palabras de la dedicatoria: "Al gaucho que llevo en mí, sacramente, como la custodia lleva la hostia." Por medio del alfabeto, el gaucho y la pampa, como Aquiles y Troya, se transforman en mitología. Asǐ termina la educación de Fabio, listo ya para empezar a escribir su novela. 


\section{NOTAS}

1. Véase por ejemplo el temprano ensayo de A. Alonso, "Un problema estilístico de Don Segundo Sombra," publicado en La Nación (Buenos Aires, 27 junio 1930) y recogido en Materia y forma en poesia (Madrid: Gredos, 1955), pp. 418-428.

2. Véase por ejemplo A. Chapman, "Pampas and Big Woods: Heroic Initiation in Güiraldes and Faulkner," Comparative Literature, 11 (1959), pp. 61-77.

3. El concepto de diglosia ha sido elaborado por el sociolingüista C. A. Ferguson en un artículo publicado en 1959 ("Diglossia," Word, 15 [1959] pp. 325-340). Se trata de la radical distinción, en ciertas culturas como la de Haití, por ejemplo, entre la lengua oral aprendida en casa y la lengua escrita aprendida en la escuela, dos lenguas que tienen funciones sociales bien diferenciadas. 
